accurately, but three points should be stressed. All subjects in the control group were in contact with haemodialysis patients for at least three months; exposure varied among the staff, but inclusion of some subjects with a relatively low exposure would only tend to blur the difference between the two groups; and inclusion in the control group was entirely independent of any prior knowledge of the ABO blood group of the subject. Furthermore, the ABO blood group distribution of the Liverpool regular dialysis treatment unit population was similar to the known $\mathrm{ABO}$ blood group frequencies in the Liverpool area. These considerations therefore suggest that subjects of group $\mathrm{O}$ are more likely to develop hepatitis, and the results of similar surveys from other haemodialysis hepatitis outbreaks will therefore be awaited with interest. Until this finding is confirmed in other units the ABO blood group should clearly not be a factor in either patient or staff selection.

$A$ relation between the liability to develop hepatitis and the ABO blood groups would suggest that host factors may be of importance in the genesis of this disease. The high frequency of hepatitis outbreaks in haemodialysis treatment units raises the possibility that the uraemic state may in some way facilitate the spread of this disease, and this again emphasizes the possible importance of host factors in predisposing to hepatitis.

It is of interest that this is not the first report of an altered ABO distribution in hepatitis. Zuckerman and McDonald (1963) found an excess of group A and a corresponding deficiency of group $O$ in 378 cases of "acute hepatitis." Their data were collected from Royal Air Force records, and the type of hepatitis was not specified. If, as seems likely, most of their cases were of infectious hepatitis, then the converse bloodgroup relationship in the present outbreak of serum hepatitis raises the possibility of antigenic differences between the respective viruses. It is, of course, possible that the blood-borne hepatitis associated with maintenance haemodialysis is in some way distinct from the commonly recognized forms.

Associations have been shown between ABO blood groups and several classes of disease, and the significance of these relationships has been discussed by Clarke (1969). Vogel et al. (1960) propounded the thesis that the present-day constitution of the $\mathrm{ABO}$ polymorphism may have been influenced by the great pandemics of the past. Thus differential susceptibility to infectious diseases such as smallpox and plague in individuals of differing blood groups may have conferred selective evolutionary advantages, and thus influenced the present distribution of the $\mathrm{ABO}$ blood groups.

Serum hepatitis may be presumed to be a disease of the era of injections, transfusions, and haemodialysis, though transplacental transmission has also been proposed (Stockes et al., 1954). Infants of mothers suffering from the disease do not usually show clinical signs of jaundice (Sherlock, 1968). An infected abortus or stillborn foetus, however, would not be jaundiced if placental function had been normal, just as jaundice does not occur in $\mathrm{Rh}$-affected foetuses in utero.

Loss of ABO incompatible zygotes (Matsunaga, 1962) would result in a progressive increase in the frequency of $O$ in succeeding generations unless offset by forces hostile to $O$. Differential susceptibility to the effects of serum hepatitis transmitted early in prenatal life might embody a selective anti-O mechanism.

We would like to thank Dr. P. O. Jones and the pathology department of Sefton General Hospital for technical help.

\section{REFERENCES}

Clarke, C. A. (1969). In Selected Topics in Medical Genetics, edited by C. A. Clarke, p. 22. London, Orford University Press.

Clarke, C. A., Edwards, J. W., Haddock, D. R. W., Howel-Evans, A. W. McConnell, R. B., and Sheppard, P. M. (1956). British Medical fournal, 2, 725.

Drukker, W., Schouten, W. A. G., and Alberts, C. (1968). In Dialysis and Renal Transplantation: Proceedings of the 5 th Conference of the European Dialysis and Transplant Association, edited by D. N. S. Kerr, p. 3. Amsterdam, Ereerpta Medica Foundation.

Jones, P. O., Goldsmith, H. J., Wright, F. K., Roberts, C., and Watson, D. C. (1967). Lancet, 1, 835.

Matsunaga, E. (1962). Eugenics Quarterly, 9, 36

Public Health Laboratory Service Report (1968). British Medical Fournal, $3,454$.

Sherlock, S. (1968). Diseases of the Liver and Biliary System, 4th ed. Oxford, Blackwell.

Stockes, J., jun., et al. (1954). Fournal of the American Medical Association, 154, 1059.

Vogel, F., Pettenkofer, H. J., and Helmbold, W. (1960). Acta Genetica et Statistica Medica, 10, 267. Zuckerman, A. J., and McDonald, J. C. (1963). British Medical fournal,
2, 537.

\title{
Bronchial Reactivity to Cigarette and Cigar Smoke
}

\author{
D. G. ROBERTSON, ${ }^{*}$ M.B., M.R.A.C.P. ; D. A. WARRELL, $\dagger$ B.M., M.R.C.P. ; JAN S. NEWTON-HOWES, $\ddagger$ B.SC. \\ C. M. FLETCHER,§ C.B.E., M.D., F.R.C.P.
}

British Medical fournal, 1969, 3, 269-271

$S^{\mathrm{u}}$ ummary: The change in specific airway conductance produced by smoking a cigarette under standard conditions was measured in 91 heavy smokers. Subsequently 19 of the most reactive subjects smoked two cigarettes with different filters and another containing cigar tobacco. The results indicated that reactivity to cigarette smoke was reduced significantly by increasing the retention efficiency of the filter and that reactivity to inhaled cigar-tobacco smoke was no less than that to cigarette smoke.

\section{Introduction}

Many studies have shown that cigarette smokers have a greatly increased morbidity and mortality rate from chronic bronchitis

\footnotetext{
* Research Fellow.

$\dagger$ Medical Registrar
† Scientific Officer.

Seader in Clinical Epidemiology.

Department of Medicine, Royal Postgraduate Medical School, London W.12.
}

and emphysema compared with non-smokers. Pipe and cigar smokers, on the other hand, have rates that are only slightly higher than those of non-smokers. McDermott and Collins (1965) found that men with symptoms of chronic bronchitis had a greater immediate increase of airway resistance on smoking one cigarette than men without such symptoms, suggesting that their increased reactivity might have been related to the development of chronic bronchitis. If this were so, it would be important to know whether smoke from different types of cigarettes or cigars produced different degrees of response. This study was designed to obtain further evidence about the bronchial reactivity to various types of cigarette, a standardized smoking procedure being used.

\section{Methods}

The subjects were male prisoners, all of whom were heavy smokers. Their ages ranged from 19 to 56 years. Those giving a history of asthma were excluded from the study. 
Cigarettes.-Cigarette X was a "filter-tip" similar to those which are now sold commercially. The retention efficiency of the filter

(R.E. $=\frac{\text { Amount of nicotine retained in filter }}{\text { Amount retained }+ \text { amount not retained }} \times 100$ )

was $50 \%$. The effects of cigarette $X$ were compared with those of a second cigarette, Y, whose filter had an R.E. of only $27 \%$. The third cigarette contained cigar tobacco and had a filter whose R.E. was $36 \%$.

\section{Screening}

During the first week of the study 91 volunteers were screened for bronchial reactivity to cigarette smoke. Three measurements of forced expired volume in the first second (F.E.V. ${ }_{1}$ ) and vital capacity (V.C.) were made with a McDermott bellows spirometer. The highest values from each man were accepted. A Medical Research Council (1966) questionnaire on respiratory symptoms was completed and the subject then entered the trailer caravan containing the body plethysmograph described by Guyatt et al. (1967).

Subjects sat in the plethysmograph with their necks slightly extended. Inspiratory airway resistance (Raw) in $\mathrm{cm} . \mathrm{H}_{2} \mathrm{O}$ / litre/second and simultaneous thoracic gas volume $(\mathrm{Vtg})$ in litres were measured at least three times while the subjects panted lightly at a frequency of $1-2 / \mathrm{sec}$. (DuBois et al., 1956a, 1956b). After these baseline measurements had been made the subjects sat in a separate compartment of the caravan, which was fitted with an extractor fan. There they smoked cigarette $\mathbf{Y}$ under supervision. After a normal exhalation to functional residual capacity the subject was instructed to fill his mouth with smoke and then to inhale as fully as possible, to total lung capacity, and to hold his breath for five seconds before exhaling. This procedure was repeated every half-minute until 10 puffs had been taken.

The subjects then returned to the plethysmograph, where measurements were repeated by the same observer two minutes after they had stopped smoking. The plethysmograph was calibrated twice a day.

Specific airway conductance (SGaw) was calculated by dividing the reciprocal of Raw by $\mathrm{Vtg}$; mean values were obtained for each subject before and after smoking. The degree of bronchial reactivity was expressed by the change in $\log _{10}$ SGaw. The reason for taking log SGaw is that SGaw has a skew distribution (Guyatt and Alpers, 1968) whereas log SGaw is more normally distributed and is therefore better for statistical purposes.

\section{Reactivity to Different Cigarettes}

The 24 most reactive subjects were selected for a second week of studies. Each smoked a different cigarette on each of three days, the order being randomized. All tests were performed at least three hours after the subject last smoked a cigarette. The reaction to the cigarette was determined in exactly the same way as in the screening procedure.

\section{Duration Response}

The duration of response to cigarette $\mathrm{Y}$ was observed in four reactors. In these subjects measurements were repeated half an hour and one hour after stopping smoking.

\section{Dose Response}

The three types of cigarettes were each smoked by three reactors. Measurements were first taken two minutes after five puffs of smoke from the cigarette, and this process was repeated twice, so that the change in SGaw could be determined after 5, 10, and 15 puffs of smoke.

\section{Results}

The 24 subjects who had the greatest change in SGaw after smoking cigarette $\mathrm{Y}$ were selected for study during the second week. They will be termed "reactors" from now on, but it should be stressed that their separation from " non-reactors" was quite arbitrary. The reactors had a change in log SGaw of -0.20 or more, which corresponds to a depression in SGaw of at least $36 \%$. Various characteristics of the two groups have been analysed in Table I. The reactors did not differ

TABLE I.-Details of Reactors and Non-reactors to Tobacco Smoke

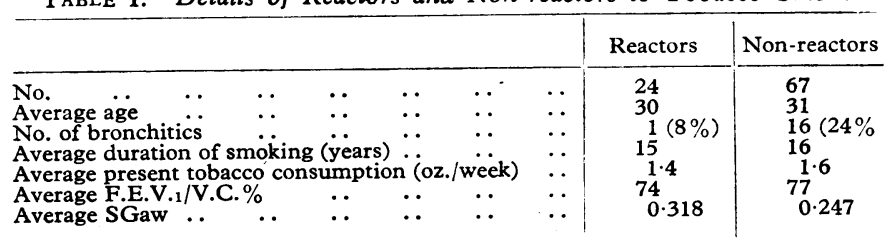

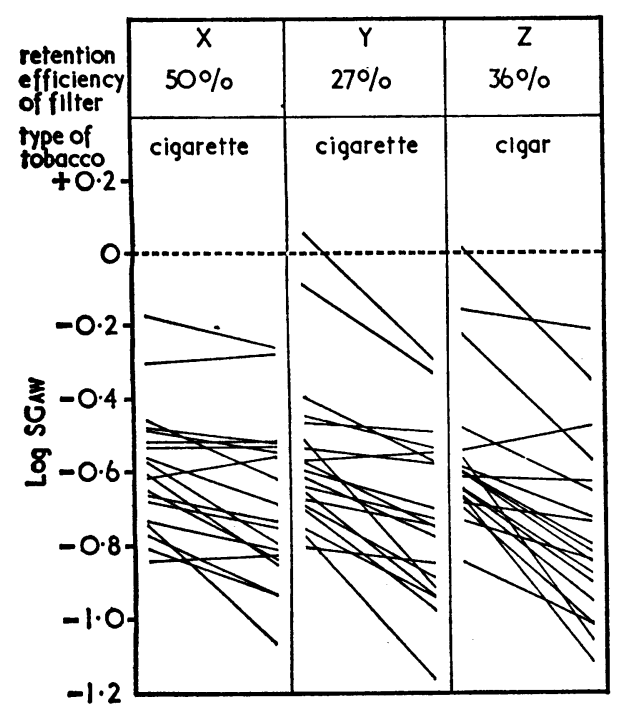

FIG. 1

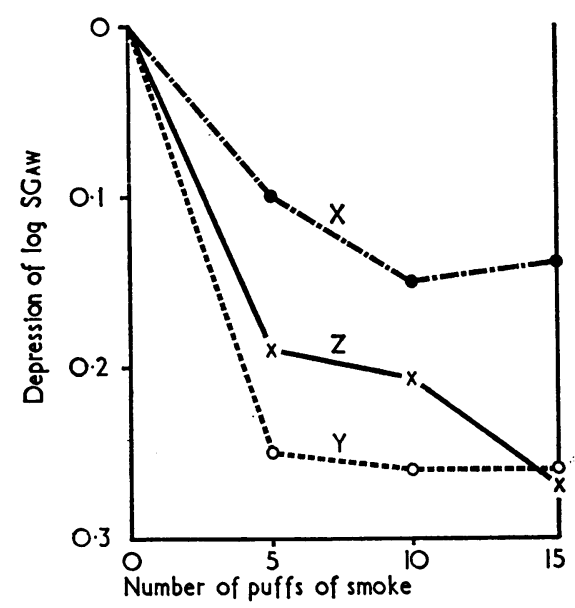

FIG. 2

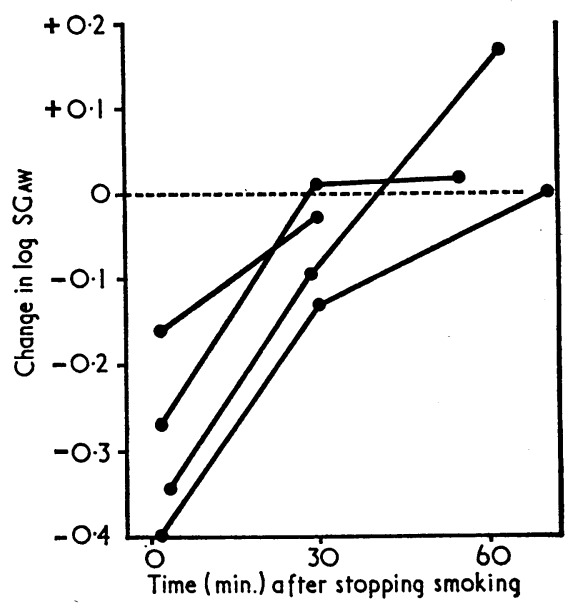

FIG. 3

FIG. 1.-Values of $\log$ SGaw in nine subjects before and after smoking three different cigarettes. Fig. 2.-Dose responses. Mean figures for three subjects after smoking three types of cigarette. FIG. 3. Changes in log SGaw in four subjects at various times after smoking cigarette Y. 
in smoking habits and did not show evidence of airway obstruction. A smaller proportion of reactors than non-reactors were bronchitic, but this apparent difference may well have been due to chance $\left(\chi^{2}=2 \cdot 18, \mathrm{P}>0 \cdot 2\right)$.

For various reasons it was possible to study only 19 of the 24 reactors during the second week. Fifteen of the 19 had no abnormal respiratory symptoms and had normal values for F.E.V.,/V.C. \%, one had simple chronic bronchitis with a normal value of F.E.V.'/V.C. \%, and three had values for F.E.V. 1 /V.C. $\%$ which were less than $70 \%$ but did not have symptoms of bronchitis. All 19 had normal values for SGaw before smoking.

The comparison of the reaction to cigarettes $\mathrm{X}, \mathrm{Y}$, and $\mathrm{Z}$ is presented in Fig. 1. The statistical details are shown in Table II. There were significant differences in the reaction between $\mathrm{X}$ and $\mathrm{Y}$ and between $\mathrm{X}$ and $\mathrm{Z}$ but not between $\mathrm{Y}$ and $\mathrm{Z}$.

\begin{tabular}{|c|c|c|c|c|c|}
\hline $\begin{array}{c}\text { Cigar- } \\
\text { ette }\end{array}$ & $\begin{array}{c}\text { Retention } \\
\text { Efficiency } \\
\text { of filter }\end{array}$ & $\begin{array}{l}\text { Type of } \\
\text { tobacco }\end{array}$ & $\begin{array}{c}\text { Mean } \\
\text { change in } \\
\text { Log SGaw }\end{array}$ & $\begin{array}{c}\text { Difference } \\
\text { between } \\
\text { means and } \\
\text { S.E. of } \\
\text { differences }\end{array}$ & Values of $t$ and $P$ \\
\hline $\begin{array}{l}\mathrm{Y} \\
\mathrm{X} \\
\mathrm{Z}\end{array}$ & $\begin{array}{l}27 \% \\
50 \% \\
36 \%\end{array}$ & $\begin{array}{l}\text { Cigarette } \\
\text { Cigarette } \\
\text { Cigar }\end{array}$ & $\begin{array}{l}-0.17 ! \\
-0.10 \\
0-.21\end{array}$ & $\begin{array}{l}0.07 \pm 0.02 \\
0.11 \pm 0.03\end{array}$ & $\begin{array}{l}\mathrm{t}^{*}=2.5,0.01<\mathrm{P}<0.05 \\
\mathrm{t}^{*}=3.9, \mathrm{P}<0.01\end{array}$ \\
\hline
\end{tabular}

Fig. 2 shows the average changes in log SGaw in three reactors after 5, 10, and 15 puffs of smoke from each of the three different cigarettes. The results in four reactors of the repeated measurements at half and one hour after stopping smoking cigarette $\mathrm{Y}$ appear in Fig. 3.

\section{Discussion}

In a comparison of the reaction produced by various cigarettes it is essential to standardize the dose of smoke to which each subject is exposed. After considering the use of spirometers and other apparatus for fixing the inhaled dose we decided that the technique described above was the most practicable. In order to standardize the dose it was necessary to impose an unaccustomed method of smoking on our subjects.
The use of a total dose of 10 puffs of smoke was suggested by preliminary studies and confirmed by the dose-response studies here reported, in which it was found to produce a maximal change in SGaw for cigarettes $\mathrm{X}$ and $\mathrm{Y}$; but for cigarette $Z$ the dose may have caused us to underestimate the reaction (Fig. 2).

The duration-response studies showed that SGaw returns rapidly to baseline after smoking stops. For this reason measurements were made two minutes after smoking had finished.

Our results indicate that reactivity to cigarette smoke is reduced significantly by increasing the retention efficiency of the filter. Cigarette $Z$, which contained cigar tobacco, produced a bronchial reaction similar to that of cigarette $\mathrm{Y}$ despite the fact that it had a filter with a greater retention efficiency. In practice, however, cigar tobacco smoke is less often inhaled and so may have less effect on airway resistance.

We consider the degree of airway obstruction resulting from tobacco smoke in these healthy prisoners to be undesirable irrespective of its possible relationship to the development of bronchial disease. Since the effect of filters is to reduce this bronchial reactivity their use may be beneficial, but our results, of course, have no bearing on the carcinogenic effect of tobacco smoke.

Our thanks are due to the Home Office for permission to perform this work, and to the prison officers and medical officers, in particular Dr. H. W. Eldridge, of Wormwood Scrubs Prison, for their help. Statistical advice was provided by Mr. M. Healy, of the Medical Research Council, Clinical Research M Centre. The computer was programmed and run by Miss Helen Pope. We are also grateful to Dr. L. E. Kagle and Dr. A. Raimondi for their help during the experiment.

\section{REFERENCES}

DuBois, A. B., Botelho, S. Y., Bedell, G. N., Marshall, R., and Comroe, J. H. (1956a). Fournal of Clinical Investigation, 35, 322.

DuBois, A. B., Botelho, S. Y., and Comroe, J. H. (1956b). Fournal of Clinical Investigation, 35, 327.

Guyatt, A. R., and Alpers, J. H. (1968). Fournal of Applied Physiology, 24, 310 .

Guyatt, A. R., Alpers, J. H., and Davies, E. E. (1967). fournal of Applied Physiology, 22, 390.

McDermott, M., and Collins, M. M. (1965). Thorax, 20, 562.

Medical Research Council (1966). Questionnaire on Respiratory Symptoms, obtainable from W. J. Holman Ltd., Dawlish, Devonshire.

\title{
Acid-base Status of Adults with Sickle-cell Anaemia
}

\author{
H. HO PING KONG,* M.B.; G. A. O. ALLEYNE, $\dagger$ M.D., M.R.C.P.
}

\begin{abstract}
Summary : Determinations of the acid-base status of 10 $\checkmark$ adult Jamaican patients with sickle-cell anaemia during "painful crisis" and after recovery showed no evidence of metabolic acidosis in the former, in contrast to reports from elsewhere. These results could explain the failure of alkalis to abort or alter the acute painful episodes of most patients with sickle-cell anaemia.
\end{abstract}

\section{Introduction}

The aetiology and treatment of the acute painful episodes ("painful crises") remain one of the major problems in patients with sickle-cell anaemia. The excruciating pains in the back, abdomen, chest, and limbs, accompanied by fever, have been well described (Diggs, 1965). Metabolic acidosis has been incriminated as the initiating cause of these painful crises (Diggs, 1965), and a report of 17 consecutive cases in painful crisis has noted that a severe metabolic acidosis was consistently present (Barreras and Diggs, 1964). It is also known that painful crises can be produced experimentally by the prolonged administration of ammonium chloride (Greenberg et al., 1957; Barreras and Diggs, 1964). As a result, the use of alkalis for the treatment and prevention of painful crises has been universally advocated (Greenberg et al., 1957 ; Greenberg and Kass, 1958 ; Nwokolo, 1960 ; Barreras and Diggs, 1964 ; Hugh-

* Wellcome Trust Grant Holder.

†ember of Scientific Staff.

Medical Research Council Tropical Metabolism Research Unit, University of the West Indies, Kingston 7, Jamaica. 